\title{
The impact of phonological awareness training on working memory in children with reading
}

\author{
Parastoo Hariri $^{1 " \text { (DD }}$, Hayedeh Saberi ${ }^{2}$, Khadijeh Abolmaali ${ }^{3}$ \\ 1. $\mathrm{PhD}$ in Educational Psychology, Roudehen Branch, Islamic Azad University, Roudehen, Iran \\ 2. Associate Professor, Department of Psychology, Roudehen Branch, Islamic Azad University, Roudehen, Iran \\ 3. Assistant Professor, Department of Psychology, Roudehen Branch, Islamic Azad University, Roudehen, Iran
}

Recieved: 22 Apr. 2017

Revised: 13 Aug. 2018

Accepted: 23 Aug. 2018

\section{Keywords}

Phonological intervention

Working memory

Reading difficulties

\section{Corresponding author}

Parastoo Hariri, PhD in Educational Psychology, Roudehen Branch, Islamic Azad University, Roudehen, Iran

Email: Parastoohariri59@gmail.com

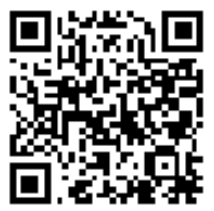

\section{Abstract}

Introduction: This study aimed to study the effectiveness of phonological interventions to improve working memory in children with reading difficulties.

Methods: The study population consisted of first-grade poor readers girl students in Tehran. Thirty students were recruited through a purposeful method ( $\mathrm{n}=15$ in 2 groups). The experimental group was received the 13 sessions of the 80 -minute training program, which developed based on phonology. Assessment instruments included Diagnostic Phonological Awareness test (Dastjerdi \& Soleimani, 2010) and Wechsler memory scale. Pretest and posttest data were analyzed using analysis of covariance.

Results: Result revealed that phonological intervention could enhance experimental groups working memory $(\mathrm{P}<0.001)$.

Conclusion: Thus, the results suggested the phonological intervention, which can be crucial to be ready for learning 


\title{
تاثير آموزش آكاهى واجى بر حافظه كارى در دانش آموزان با مشكلات خواندن
}

\author{
يرستو حريرى"'D(D) ، هايده صابرى'، خديجه ابوالمعالى'
}

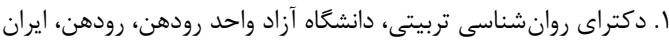

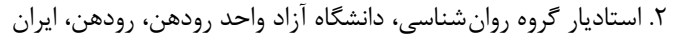

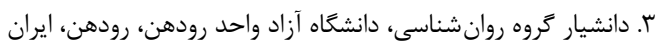

مقلدمه: اين يُوهش با هدف مطالعه اثربخشى مداخلات آموزش واجَآكاهى بر بهبود حافظه كارى دانشآموزان با مشكلات خواندن انجام كرفت.

روش كار: به اين منظور •r دانشآموز دختر پايه اول ابتدايى كه بر اساس جى ليست نارساخوانى علايم مشكلات يادكيرى را داشتند به روش هدفمند كزينش و به تصادف در دو گروه آزمايش و كنترل (هر گروه ها نفر) جاى كرفتند. افراد كروه آزمايش در سا جلسه •^د دقيقهاى بر اساس برنامه تدوين شده آموزشهاى واجشناختى دريافت نمودند. نمرات

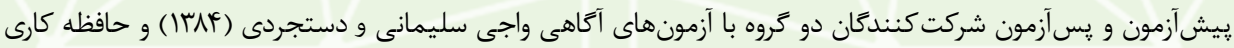

$$
\text { وكسلر جمعآورى شد. }
$$

يافته ها: دادههاى حاصل از اجراى آزمونها با روش تحليل كوواريانس، اثربخشى مداخلات واجشناختى بر حافظه كارى

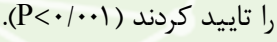

نتيجه كَيرى: با توجه به اثربخشى مداخلات واجشناختى در حافظه كارى و نقش همزمان در بهبود خواندن مىتوان ادعا كرد برداختن به آموزشهاى واجشناختى در طول سال اول تحصيل و يا حتى بيش از دبستان ضرورى مىنمايد.

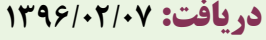
اصلاح نهايى:

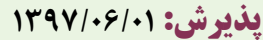

$$
\text { وازههاى كليدى }
$$$$
\text { مداخلات آكاهى واجى }
$$

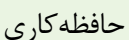

مشكلات خواندن

$$
\text { نويسنده مسئول }
$$

يرستو حريرى، دكتراى روانشناسى تربيتى،

$$
\text { دانشخاه آزاد واحد رودهن، رودهن، ايران }
$$

ايميل:Parastoohariri59@gmail.com

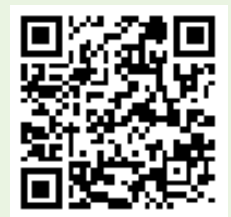

dol doi.org/10.30699/icss.21.2.52
كلمات، مشكل در صداكشى كردن وازه) ז. مشكل در فهم معناى آن جيزى كه خوانده شده است (جنانجه متن را به طور درست هم بخواند اما از فهمم توالى، ارتباط، نتيجه، يا معناى عمقى آن جيزى كه خوانده ناتوان باشد) rا. مشكل در هجى كردن (ممكن است صامت يا مصوتى را اضافه كند، حذف كند و يا با صامت و مصوت ديخرى جانشين كند)
مشكل خواندن در پايههاى ابتدايى از علل اصلى شكست تحصيلى و حتى مشكلات رفتارى و خلقى است. ضعف خواندن بر اساس پنجمين راهنماى تشخيصى اختلالات روانى با اين ويزگى ها مشخص مىشود: ا. غلط يا آهسته خواندن و تقلاى زياد براى خواندن وازه (مثلا خواندن غلط تكىوازه يا آهسته خواندن و يا با ترديد خواندن، حدس زدن مكرر 
حافظه كارى است كه اطلاعات كلامى را نكهدارى مى كند. محدوديت دامنهعمومى در آنجه كه بر "مولفه اجرايى" حافظه كارى دلالت دارد

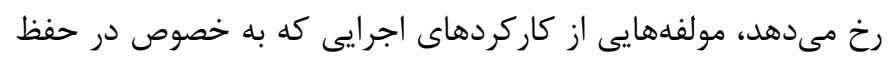

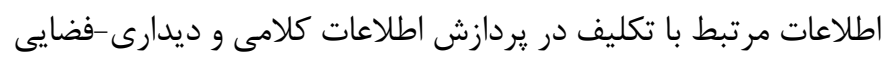

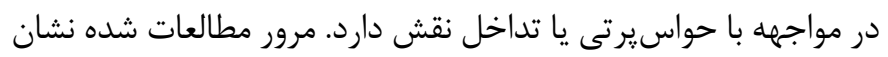

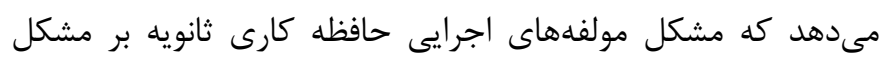

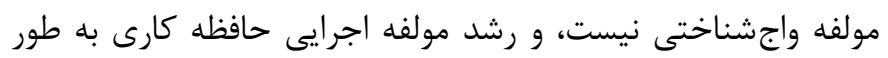

معنادارى با رشد خواندن مرتبط است (I آ). يزوهشها نشان دادهاند كه تقويت حافظه كارى در بهبود خواندن (بازشناسى وازثه، افزايش توانايى درى متن) و همجنين بهبود حافظه كارى ديدارى و شنيدارى موثر بوده است به طور مثال ميرمهدى و

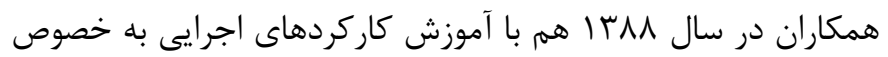

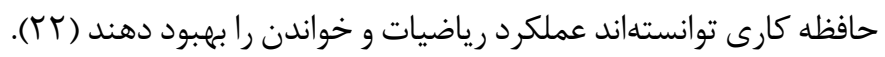

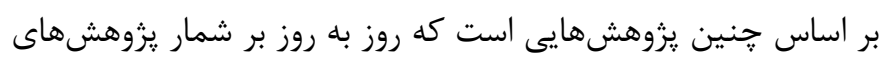

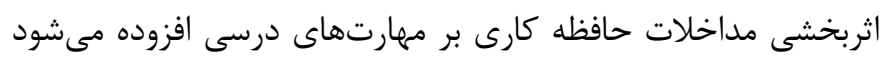

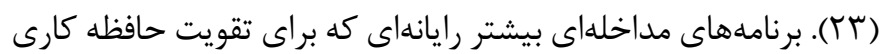

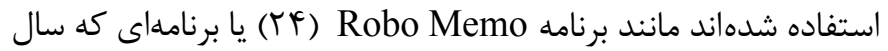
11499 توسط موسسه تحقيقاتى رفتارى_شناختى سينا طراحى شده،

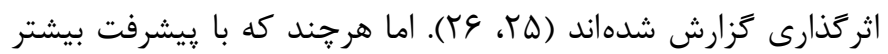
نظام آموزشى و مداخلهاى و دسترسى به رايانه و بازىهاى رايانهاى تقويت حافظه كارى هم بيشتر شده است اما هنوز هم دسترسى بـ به آنها

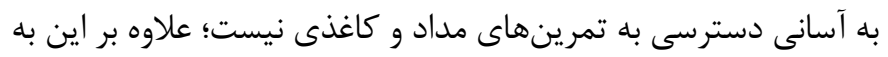

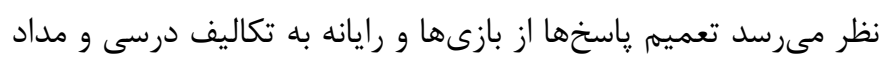

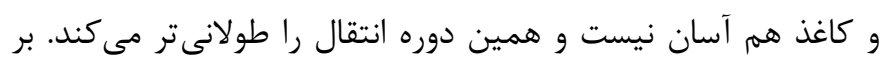

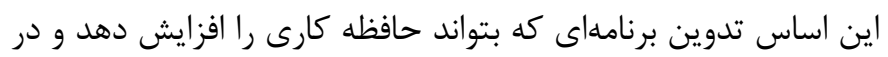

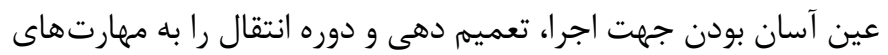
درسى را همم آسان و كوتاه كند ضرورى به نظر مىرسد. با اين ديد أهاه و با توجه به اينكه حلقه آكاهى واجى از اجزاى تشكيل دهنده حافظه كارى مىباشد و جنانجه قبلا هم به همبستكى ههارتهاى واجشناختى و

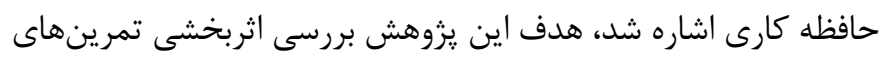
واجشناختى در بهبود عملكرد حافظه كارى بود.

\section{روش كار}

طرح اين يزوهش از نوع طرح بيش آزمون_يس آزمون همراه يِيخيرى

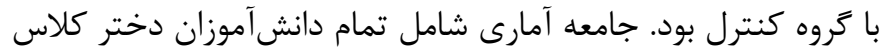
اول ابتدايى شهر تهران بود كه بر اساس ارزيابىهاى انجام شده در

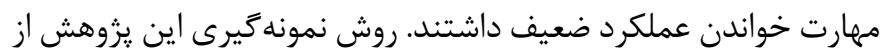

(1). شيوع اختلالات خواندن بين جامعه دانشآموزى ايران /| \درصد

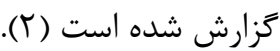
خواندن زيربنايى عصب شناختى دارد، طورى كه فرض بر اين است كه

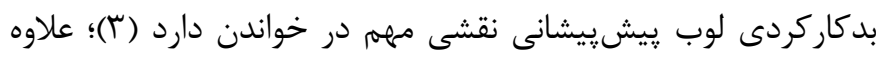

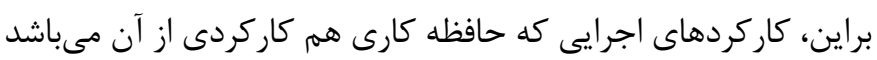

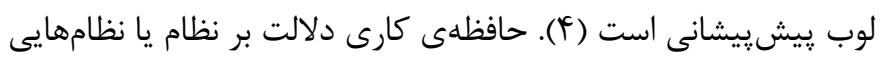

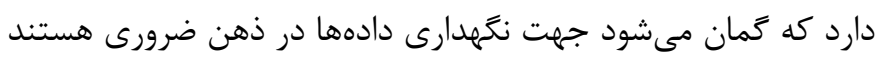
تا تكاليفى جون استدلال، درك يا يادكيرى تكميل شود (ه). حافظهى

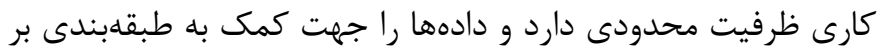
اساس اطلاعات موجود يا جديد، يردازش مىكند (9). شواهدى وجود دارد كه نشان مىدهند اهميت مشكلات مربوط به حافظه كارى و

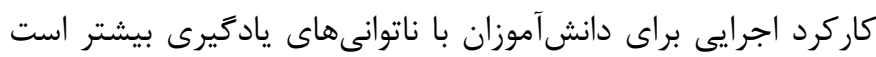

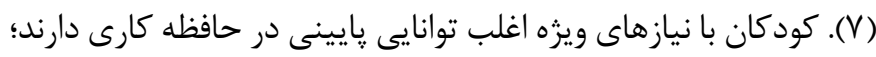

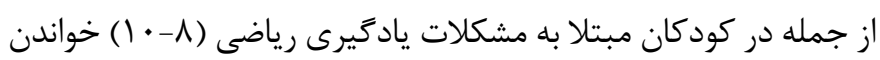

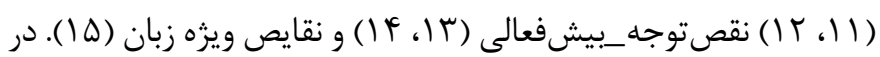

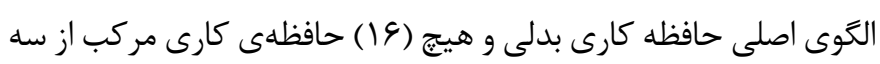
جزء صفحه ديدارى_فضايى، مجرى مركزى و حلقه واجى است. نتايج يك فرا تحليل نشان مى دهد مجرى مركزى براى يادكيرى اوليه خواندن و حافظه كارى كلامى براى مهارت يافتن در خواندن مهمم هستند و علاوه بر اين براى عملكرد دانشآموزان در مدرسه حافظه كارى بسيار مهامهم

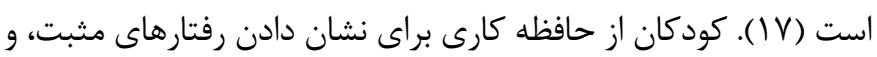
انجام تكاليف درسى در كلاس استفاده مى كنند (1) (1).

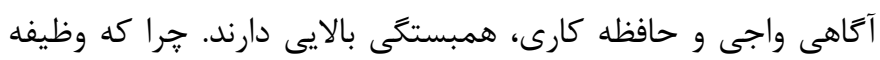

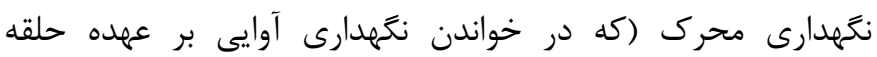

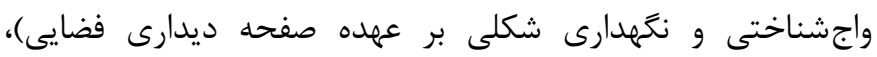
دستكارى آن، ارتباط دادن محرك با دانش موجود در حافظه بلند مدت و در نهايت توليد ياسخ واجى بر عهده حافظه كارى است؛ بنابراين إناطن حافظه كارى قوى خواندن را تسهيل مى كند (9 (). از طرفى از تكاليف اصلى سنجش، تقويت حافظه كارى تكاليف و تمرينهاى واجشناختى است مانند فراخناى ارقام جهت سنجش، و يا تكرار ناكلمات يا هجاهاى

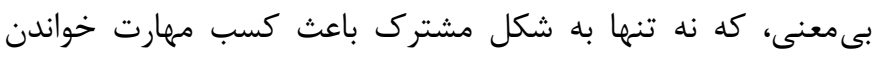

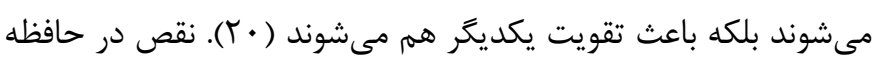

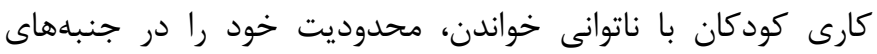
خاص (مانند دسترسى ناكارآمد به بازنمايىهاى واجى) و محدوديت داريت دامنهعمومى (ناكارآمدى در نظارت و به روز رسانى اطلاعات ديدارى و كلامى) نشان مىدهد. محدوديت دامنه خاص در آنجه كه بر اهلقه واجشناختى" دلالت دارد رخ مىدهد؛ حلقه واجشناختى جزئى از 


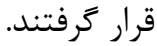
جزئيات اطلاعات جمعيت شناختى • ب دانشآموز در جدول آ آمده است:

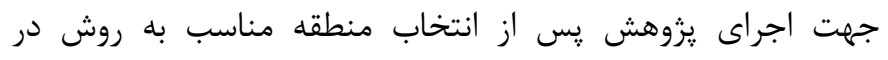

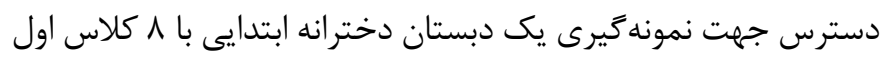

نوع نمونه گيرى هدفمند است. نمونهاى ثروهش شامل •r دانش آموز دختر پايه اول بودند كه بر اساس معيارهاى معلمان پايه اول در خواندن عملكرد غيرقابل قبول داشتند ولى هيج تشخيصى دريافت نكرده بودند،

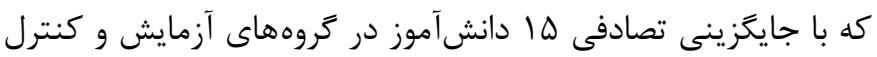

جدول ا. اطلاعات جمعيت شناختى نمونها

\begin{tabular}{|c|c|c|}
\hline ميانَّين土|نحراف هوش ريتاندارن & ميانخين +انحراف استاندارد & \\
\hline$\Delta / \Delta F \pm 1 \cdot \varepsilon / 1 T$ & $\cdot \mid 9 \cdot \pm \mathrm{V} / \cdot 1$ & آزمايش \\
\hline$G / T r \pm 1 \cdot F / V G$ & $\cdot \mid f F \pm G / \Lambda V$ & كنترل \\
\hline
\end{tabular}

و آلفاى كرونباخ محاسبه شده است. در روش آزمون_بازآزمون كه

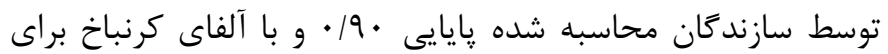

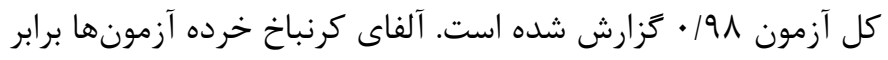

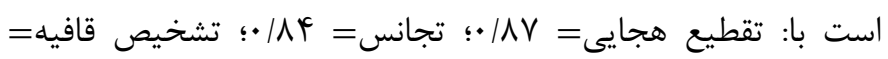

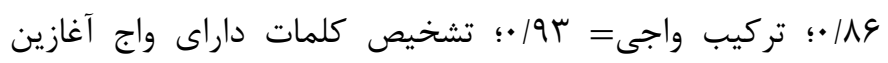

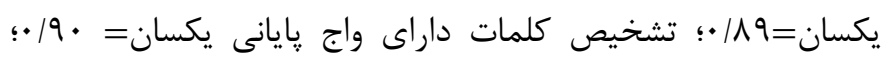

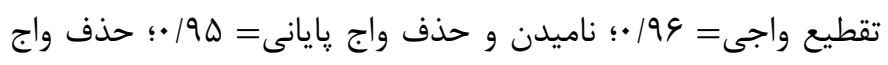

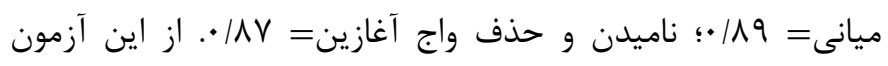

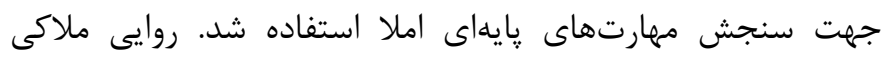

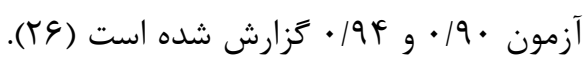

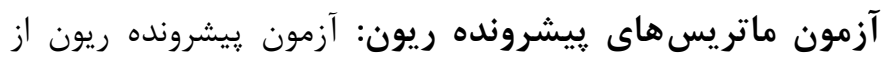

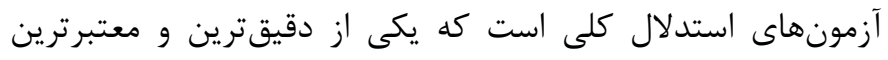

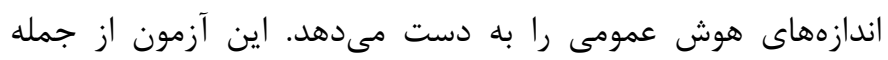
آزمونهاى هوش غير كلامى است كه ريون در انغلستان ساخته است.

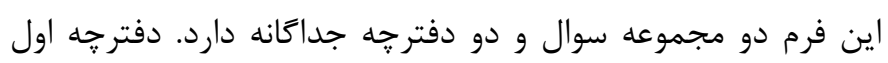

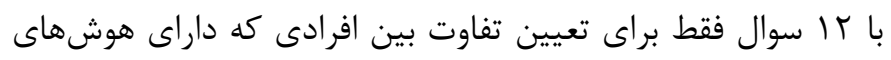

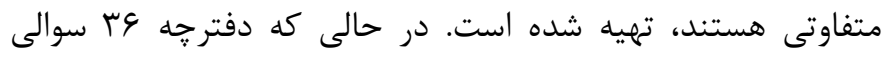

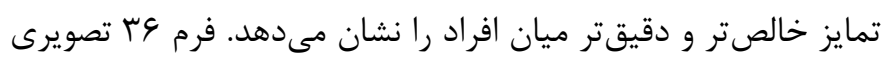

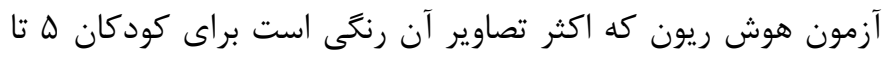

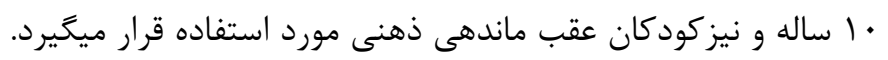

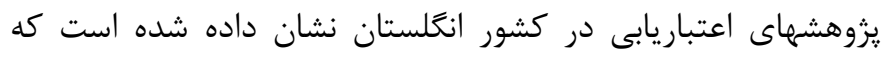

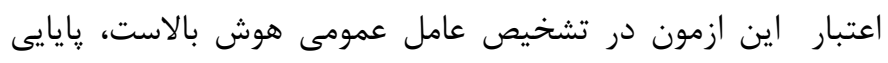

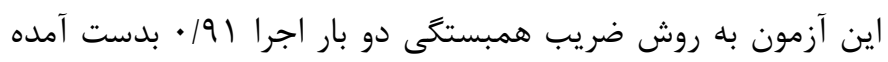

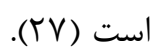
آزمون هوش وكسلر: نسخه فارسى مقياس هوش وكسلر در سال
با ع ا أدانشآموز انتخاب و از معلمان קايههاى اول خواسته شد تا تمام

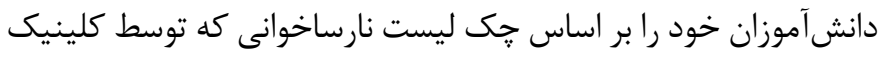

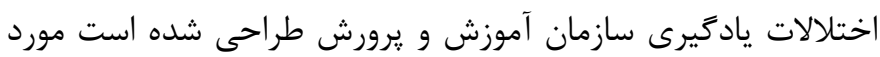

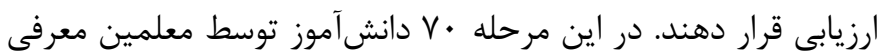

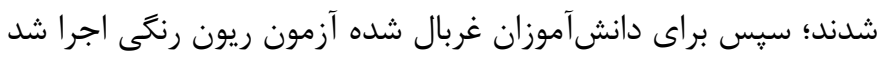

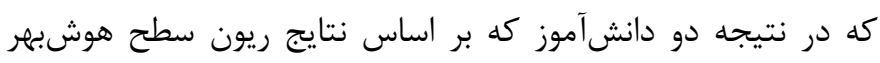

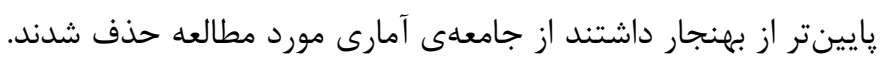

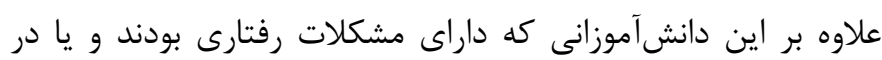

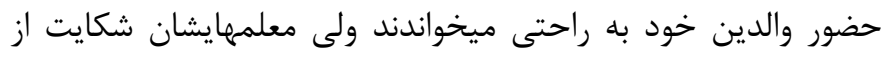
ناتوانى در ارتباط برقرار كردن و خواندن دركلاس داشتند نيز حذف آن إندان شدند. در نهايت يروندهى دانشآموزان معرفى شده، بررسى شد و از از داز

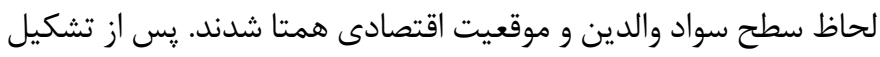

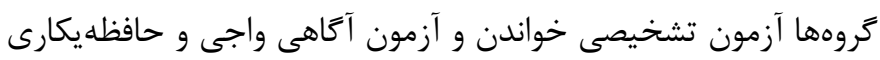

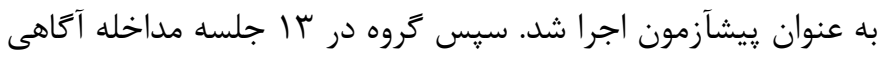

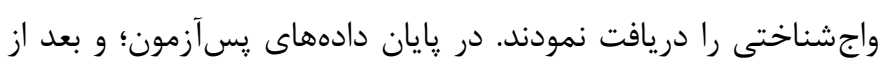

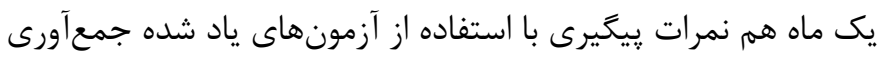
و تحليل شد. آزمون آكاهى واجشناسى: اين آزمون توسط سليمانى و دستجردى

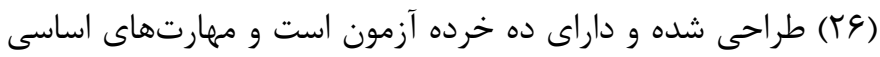

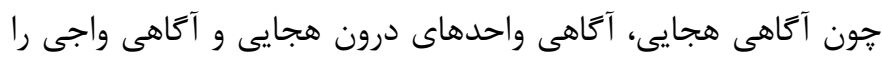

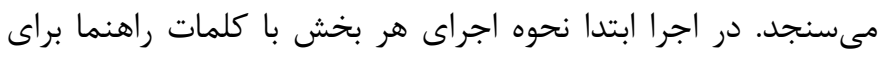

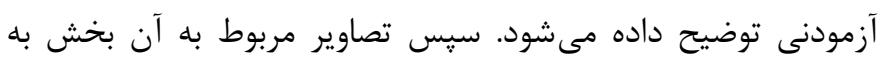

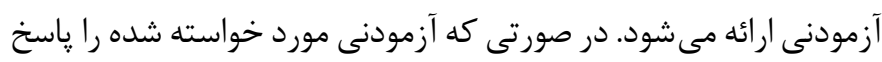

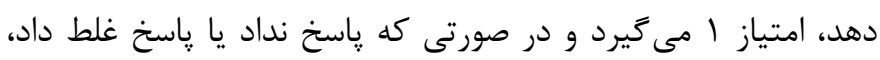

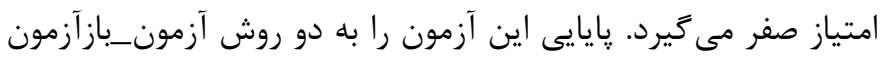




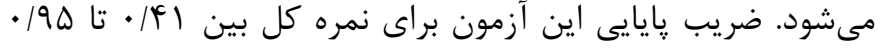
محاسبه شده است (؟9). مداخله آكاهى واجهناختى: برنامه مداخله شامل برنامه آكاهى واجشناختى است، آموزش واجشناختى بر اساس توصيههاى موجود

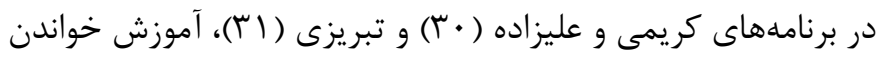

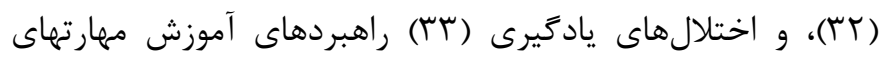
زبانى (TF) طراحى شد. برنامه يس از تدوين، جهت بررسى روايى

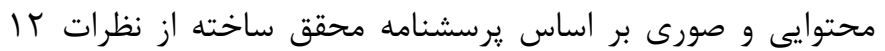
استاد متخصص در آموزش دانشآموزان و نيز آموزكاران پايه اول ابتدايى استفاده شد. يس از جمعآورى نظر متخصصين و اعمال تغييرات جزيى برنامه جهت اجرا براى دو كروه در سيزده جلسه آماده شد. طول مدت هر جلسه از هر كدام از برنامه ها برابر با • م دقيقه بود

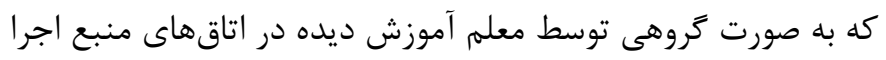

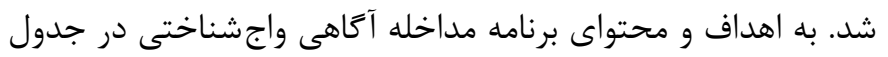

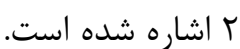

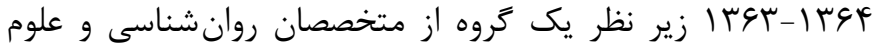
تربيتى در دانشخاه شيراز ترجمه و انطباق داده شد. به منظور تعيين

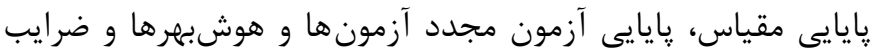

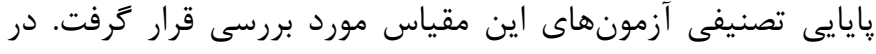

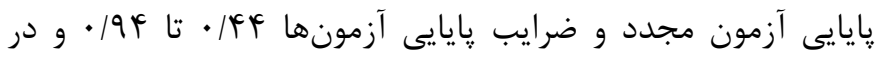

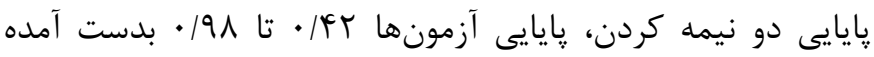
است. در بررسى اعتبار همزمان اين مقياس با مقياس وييسى ضرايب إنايب همبستخى هوش بهرهاى كلامى، عملى و كل دو مقياس به ترتيب

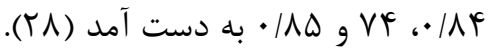
جك ليست نارساخوانى: اين جى ليست ابزار غربال گرى است كه براى دانشآموزان مشكوك به نارساخوانى به كار مىرود و در كلينيك آنسي

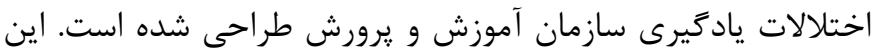

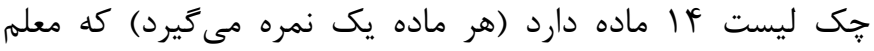

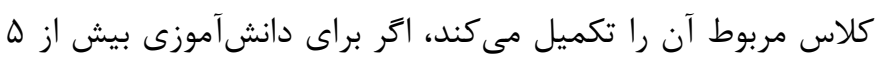
ماده علامت زده شود آن دانشآموز مشكوك به نارساخوانى شناخته

جدول r. اهداف و محتواى جلسات

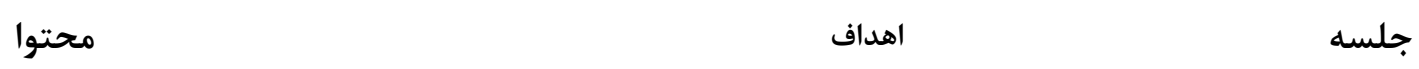

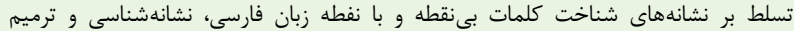

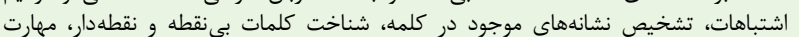

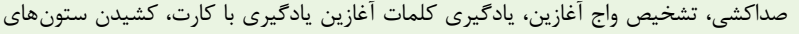

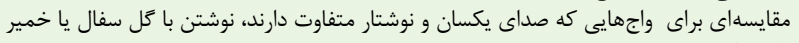
بازى يا جعبه شن.

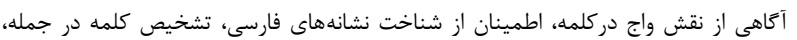

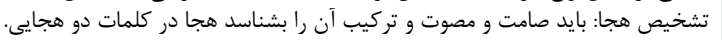

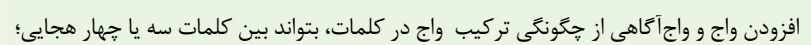

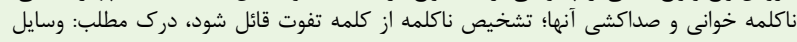

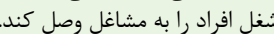

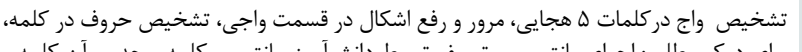

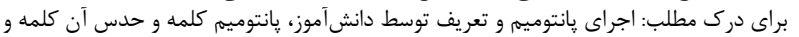

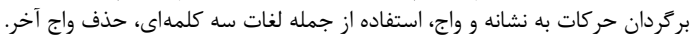

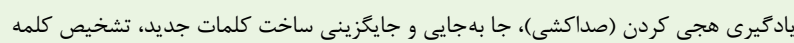

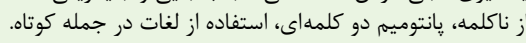

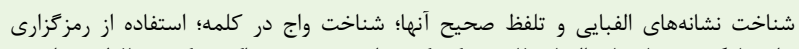

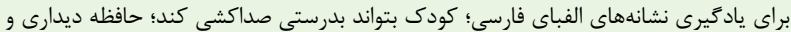

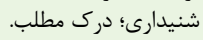

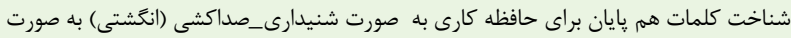

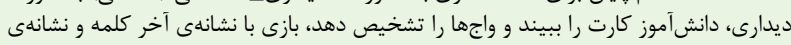

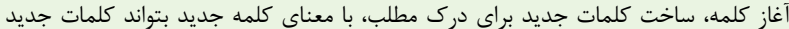

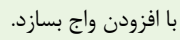

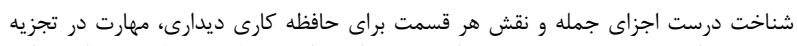

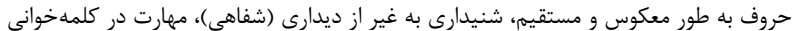

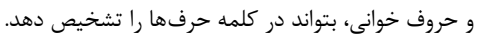

جهارم

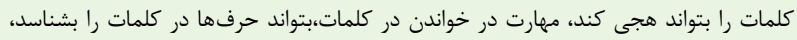

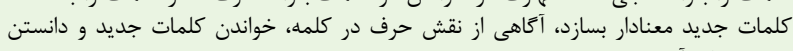
درك معناى آن. 
ادامه جدول r. اهداف و محتواى جلسات

\begin{tabular}{|c|c|c|}
\hline محتوا & 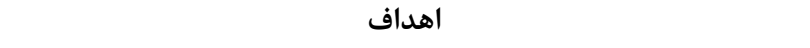 & 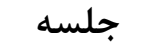 \\
\hline خواندن كلمات f هجايى، تركيب واجهاى جداكانه براى ساخت كلمه & 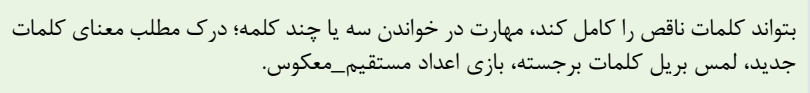 & هفتم \\
\hline شنيدارى دو هجايى، درك باق حطلب. مناسب، تركيب درست دو حرف، جايكزينى هجا/تشخيص & 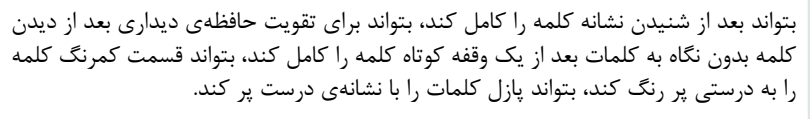 & 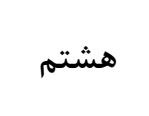 \\
\hline 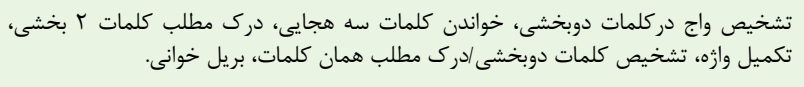 & 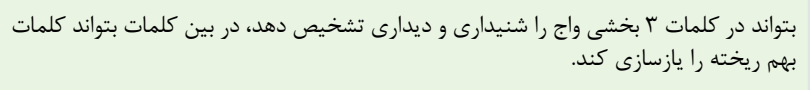 & نهمי \\
\hline 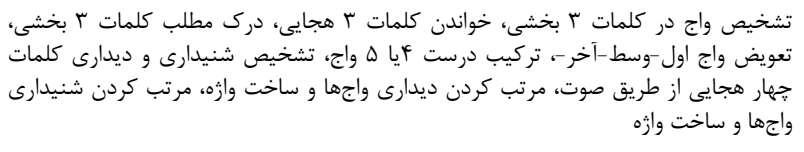 & 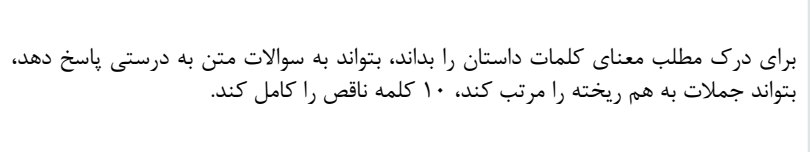 & 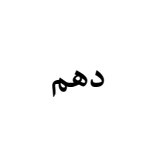 \\
\hline 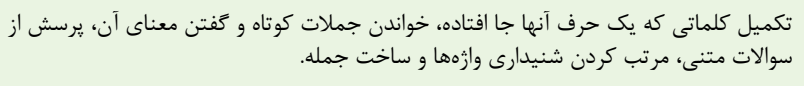 & بتواند كلمات با ץ جاى خالى را يركند، بتواند كلمات خواسته شده را از متن بيدا كند. & 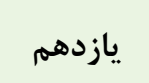 \\
\hline كلمركر شنيده شده در جلم متن خالى، خواندن متن كوتاه، يرس سوال از متن شنيده شده، جستجوى & 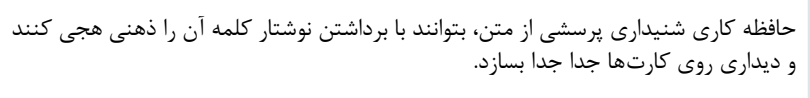 & سوازدهم و \\
\hline
\end{tabular}

يافته ها

رد كرد. نتايج تحليل كوواريانس در جدول بأ ارائه شده است.

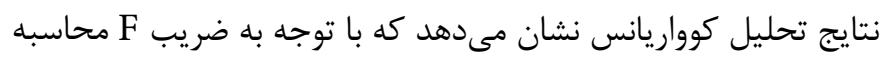

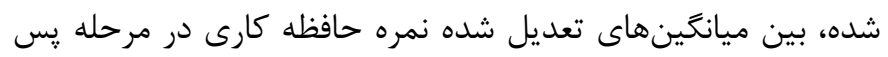

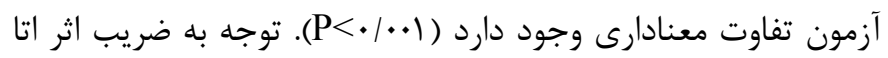

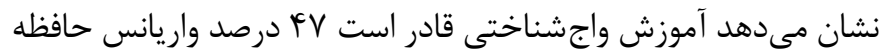
كارى را تبيين كند.
ميانكين و انحراف معيار نمرات بيشآزمون و پِ پآزمون حافظه كارى در جدول ب ارائه شده است. جهت رعايت ييشفرضهاى استفاده از آزمون تحليل كوواريانس از آزان

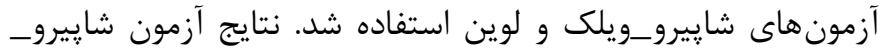
ويلك برابر با V••• نرمال بودن توزيع نمرات رانشان داد، و نتايج آزمون

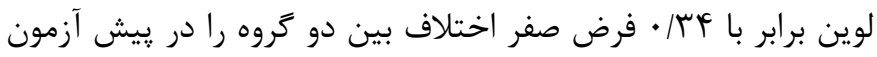

جدول זّ. ميانكَين و انحراف معيار نمرات بِيشآزمون و پِسآزمون حافظه كارى دو كَروه

\begin{tabular}{|c|c|c|c|c|c|c|}
\hline \multicolumn{2}{|c|}{ انحراف معيار } & \multicolumn{2}{|c|}{ ميانغين } & \multicolumn{2}{|c|}{ تعداد } & \multirow{2}{*}{ كروه } \\
\hline يس آزمون & קيش آزمون & يس آزمون & پِيش آزمون & يس آزمون & ييش آزمون & \\
\hline$r / Q 9$ & $T / N I$ & $\mid r / r$. & 1.1 .9 & 10 & 10 & آزمايش \\
\hline$r / 9 T$ & $r / 19$ & $1 . / 14$ & 9/9. & 10 & 10 & كنترل \\
\hline
\end{tabular}




\begin{tabular}{|c|c|c|c|c|c|c|}
\hline ضريب اثر اتا & $\mathbf{P}$ & $\mathbf{F}$ & مجذانگين & درجه آزادى & مجذورات مجموع & منبع تغيير \\
\hline$\cdot|V|$ & $\cdot 1 \cdot \cdot 1$ & ब9/9 & IrG/KF & 1 & IrG/KF & بيش آزمون \\
\hline \multirow[t]{3}{*}{$\cdot / 4 V$} & $\cdot 1 \cdot \cdot 1$ & $r r / \cdot V$ & $r q / \cdot r$ & 1 & $r q / \cdot r$ & كروه \\
\hline & & & $r / \cdot r$ & TV & $\Delta F / q q$ & خطا \\
\hline & & & & $r$. & Fr人e & كل \\
\hline
\end{tabular}

آن پيش از آموزش رسمى خواندن، ادعا كرد ضرورى است پيش از برجسب زدن و ادعاى اينكه دانشآموزى به علت مشكلى جون اختلالات يادكيرى در خواندن پيشرفت لازم را ندارد دانش آموز را در معرض مداخلات واجشناختى قرار دهيم مانند آنجه كه الگوى ياسخ به مداخله ادعا مى كند. البته با يك ديدگًاه يِيشخيرانه مىتوان ادعا كرد، اگر ارائه اين مداخلات ييش از دبستان باشد از آمار دانشآموزان

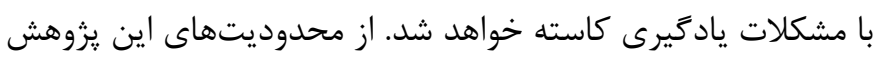
عدم تفكيك خرده مهارتهاى حافظه كارى است كه همين امر سبب مىشود نتوان ادعا كرد كه كدام يك از خرده مهارتهاى عددى، الفبايى يا فضايى بهبود يافته است. بنابراين به يروهشگران توصيه

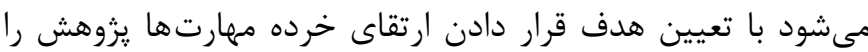

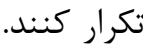

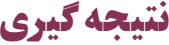

با توجه به اثربخشى مداخلات واجشناختى در حافظه كارى و نقش همزمان در بهبود خواندن مىتوان ادعا كرد يرداختن به آموزشهاى واجشناختى در طول سال اول تحصيل و يا حتى ييش از دبستان ضرورى مىنمايد. علاوه بر اين با توجه به ويزگى هايى جون ارزان و

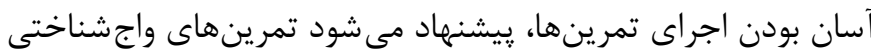
به شكل فعاليتهاى مكمل مهارتهاى درسى، در كلاسهاى آموزش عمومى به كار زرفته شوند تا علاوه بر نقش مستقيم در ارتقاى عملكرد تحصيلى بتوانند با تقويت حافظه كارى نيز به شكلى ديگر به بهبود عملكرد تحصيلى كمك كنند.

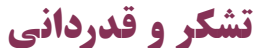

نويسندًان از اولياى مدارس و والدين دانشآموزان شركت كننده در يزوهش كمال تشكر و قدردانى دارند.
اين يزوهش با هدف مطالعه اثر بخشى آموزش واجشناختى بر بهبود

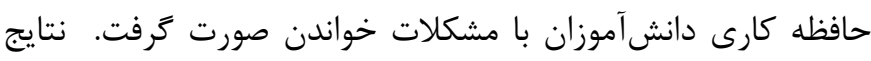
حاكى از اثربخشى آموزشهاى واجشناختى در ارتقاى حافظه كارى

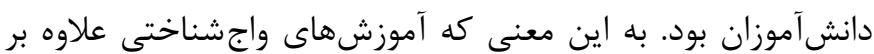
نقش ير رنگ در ارتقاى مهارتهاى خواندن مىتوانند حافظهكارى را نيز بهبود ببخشند (هاr، عץ). اين نتيجه با نتايج Park و همكاران

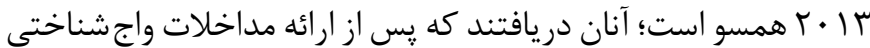
عملكرد دانشآموزان با نقص ويزه زبانى بهبود معنادارى يافته است

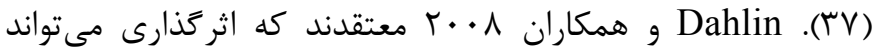
ناشى از اين هميوشانى مناطق مغزى خواندن و كاركردهاى اجرايى

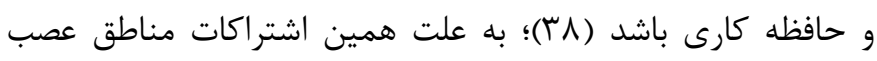

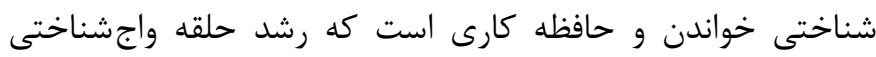
حافظه كارى، نياز اوليه و اساسى خواندن محسوب مىشود و همين إسنا اشتراك مناطق و ويش نياز بودن رشد حلقه واجشناختى مىتواند همبستىى مهارتهاى واجشناختى و حافظه را هم نشان دهد (9 (ب). از طرفى هم انجام تمرينهاى واجشناسى مانند تشخيص صداى اول يا آخر، جايگزينى واجها، يِيدا كردن وازمهاى هم قافيه از بين

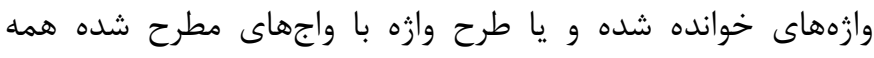
مستلزم كمك گيرى از حافظه كارى مىباشند. به بيان ديكر حتى

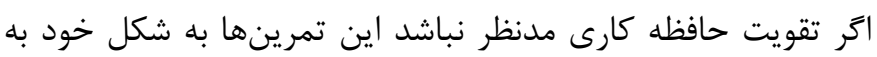

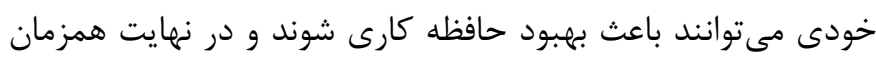
با تقويت خواندن يا املا حافظه كارى هم تقويت مى شودان يعنى عملكرد درسى در كل از دو جهت ارتقا مى يابد: اول با تقويت مهارت واجشناختى و دوم تقويت حافظه كارى. بنابراين كاربرد اين جنين برنامهاى بسيار اقتصادى و موثر مىباشد. در رابطه با بهبود همزمان دو مهارت خواندن و ظرفيت حافظه كارى با يك برنامه مداخله شايد

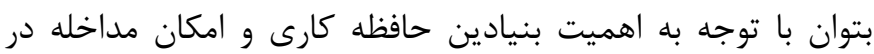




\section{References}

1. American Psychiatric Association, 2013. Diagnostic and Statistical Manual of Mental Disorders 5th Edition:DSM-5®. American Psychiatric Pub, Arlington VA.

2. Rahimian Boogar E, Sadeghi A. Prevalence of reading disorder in primary school students. Iranian Journal of Psychiatry and Clinical Psychology. 2007;12(4):396-402. (Persian)

3. Jorm AF. The cognitive and neurological basis of developmental dyslexia: A theoretical framework and review. Cognition. 1979;7(1):19-33.

4. Lara AH, Wallis JD. The role of prefrontal cortex in working memory: A mini review. Frontiers in Systems Neuroscience. 2015;9:173

5. Baddeley A. Working memory. Current Biology. 2010;20(4):136-140.

6. Baddeley AD. Logie. RH. Working memory: The multiple-component model. In Miyake A \& Shah P, editors. Models of working memory: Mechanisms of active maintenance and executive control. New York:Cambridge University Press;1999. (pp. 28-61)

7. Alloway TP, Gathercole SE, Adams AM, Willis C. Working memory abilities in children with special educational needs. Educational and Child Psychology. 2005;22(4):56-67.

8. McLean JF, Hitch GJ. Working memory impairments in children with specific arithmetic learning difficulties. Journal of Experimental Child Psychology. 1999;74(3):240-260.

9. Andersson U, Lyxell B. Working memory deficit in children with mathematical difficulties: A general or specific deficit? Journal of Experimental Child Psychology. 2007;96(3):197228.

10. Bull R, Scerif G. Executive functioning as a predictor of children's mathematics ability: Inhibition, switching, and working memory. Developmental Neuropsychology. 2001;19(3):273-293.

11. Gathercole SE, Alloway TP, Willis C, Adams AM. Working memory in children with reading disabilities. Journal of Experimental Child Psychology. 2006;93(3):265-281.
12. Dahlin KI. Effects of working memory training on reading in children with special needs. Reading and Writing. 2011;24(4):479-491.

13. Martinussen R, Hayden J, Hogg-Johnson S, Tannock R. A meta-analysis of working memory impairments in children with attention-deficit/hyperactivity disorder. Journal of the American Academy of Child \& Adolescent Psychiatry. 2005;44(4):377-484.

14. Martinussen R, Tannock R. Working memory impairments in children with attention-deficit hyperactivity disorder with and without comorbid language learning disorders. Journal of Clinical and Experimental Neuropsychology. 2006;28(7):10731094.

15. Weismer SE, Evans J, Hesketh LJ. An examination of verbal working memory capacity in children with specific language impairment. Journal of Speech, Language, and Hearing Research. 1999;42(5):1249-1260.

16. Baddeley AD, Hitch G. Working memory. Psychology of Learning and Motivation. 1974;8:47-89.

17. Peng P, Barnes M, Wang C, Wang W, Li S, Swanson $\mathrm{HL}$, et al. A meta-analysis on the relation between reading and working memory. Psychological Bulletin. 2018;144(1):48-76.

18. Vandenbroucke L, Verschueren K, Desoete A, Aunio $\mathrm{P}$, Ghesquière $\mathrm{P}$, Baeyens $\mathrm{D}$. Crossing the bridge to elementary school: The development of children's working memory components in relation to teacher-student relationships and academic achievement. Early Childhood Research Quarterly. $2018 ; 42: 1-10$.

19. Fletcher JM. Classification and identification of learning disabilities. In: Wong B, Butler DL, editors. Learning about Learning Disabilities. 4th ed. Massachusetts:Academic Press;2012. pp. 1-25.

20. Kamyabi M, Teimory S, Mashhadi A. The effectiveness of working memory training on decreasing reading problems and improving working memory in dyslexic students. Exceptional Education. 2014;2 (124):33-41. (Persian) 
21. Meltzer L. Executive function in education: From theory to practice. 2nd ed. New York:Guilford Press;2018.

22. Mirmehdi SR, Alizadeh H, Seif Naraghi M. The impact of training executive functions on mathematics and reading performance in primary students with specific learning disabilities. Journal of Exceptional Children. 2009:9(1):1-12. (Persian)

23. Klingberg T, Fernell E, Olesen PJ, Johnson M, Gustafsson P, Dahlström K, et al. Computerized training of working memory in children with ADHD-a randomized, controlled trial. Journal of the American Academy of Child \& Adolescent Psychiatry. 2005;44(2):177-186.

24. Klingberg T, Forssberg H, Westerberg H. Training of working memory in children with ADHD. Journal of Clinical and Experimental Neuropsychology. 2002;24(6):781-791.

25. Hossein Khanzadeh AA, Azadimanesh P, Mohammadi H, Ahmadi S, Sadeghi S. The effectiveness of programs to strengthen working memory and visual perception on improving reading students with reading disorder. Quarterly Journal of Psychological Studies. 2016;12(2):49-66. (Persian)

26. Soleimani Z, Dastjerdi KM. Determination of the validity and reliability of phonological awareness test. Journal of Psychology. 2005;9(1):82-100. (Persian)

27. Rahmani J, Abedi MR. Color Raven standardized test for children 5 to 10 years old in Isfahan. Journal of Quarterly Teachings. 2004;23:81-86. (Persian)

28. Shahim S. Adaptation and standardization of the Wechsler Intelligence Scale for Children. Journal of Social Sciences and Humanities of Shiraz University. 1992;7(1-2):123-154. (Persian) 29. Azizian M, Abedi MR. Construction and standardization of reading level diagnostic test for third grade primary school children. Iranian Journal of Psychiatry and Clinical Psychology. 2006;11(4):379-387. (Persian)

30. Karimi B, Alizadeh H. Spelling learning Disorder (Assess- ment and Instruction). Tehran:Ravan:2013. (Persian)

31. Tabrizi M. Treatment of reading disorders. Tehran:Fararavan;2013. (Persian)

32. Sangary MR, Alizadeh FS. Reading Instruction (Reading Method). 16th ed. Tehran:Aboata;2015. (Persian)

33. Hallahan DP, Lloyd JW, Kauffman JM, Weiss MP, Martinez EA. Learning disabilities: Foundations, characteristics, and effective teaching. 3rd ed. Boston:Pearson. 2004.

34. Safapour A. Secondary school Persian language skills training strategies: For teachers, educators, and students of educational centers. Tehran:Research and Educational Planning Organization;2000. (Persian)

35. Hsu LS, Ip KI, Arredondo MM, Tardif T, Kovelman I. Simultaneous acquisition of English and Chinese impacts children's reliance on vocabulary, morphological and phonological awareness for reading in English. International journal of Bilingual Education and Bilingualism. 2019;22(2):207-223. 36. Kjeldsen AC, Kärnä A, Niemi P, Olofsson Å, Witting K. Gains from training in phonological awareness in kindergarten predict reading comprehension in grade 9. Scientific Studies of Reading. 2014;18(6):452-467.

37. Park J, Ritter M, Lombardino LJ, Wiseheart R, Sherman S. Phonological awareness intervention for verbal working memory skills in school-age children with specific language impairment and concomitant word reading difficulties. International Journal of Research Studies in Language Learning. 2014;3(4):3-22.

38. Dahlin E, Neely AS, Larsson A, Bäckman L, Nyberg L. Transfer of learning after updating training mediated by the striatum. Science. 2008;320(5882):1510-1512.

39. Baddeley A, Gathercole S, Papagno C. The phonological loop as a language learning device. Psychological Review. 1998;105(1):158-173. 